\title{
Navigating Through the Maze: Practical Constraints in the Implementation of Forest Regulations (FLEGT) in Ghana
}

\author{
Gordon Kofi Sarfo-Adu \\ Corporate Planning Manager \\ Department of Corporate Planning, Monitoring and Evaluation \\ Forestry Commission, Ghana \\ Tel: 233-244-286-127/233-208-420-472 \\ E-mail: gsarfoadu.hq@fcghana.org/gsarfoadu@gmail.com
}

Received: January 5, 2021 Accepted: February 10, 2021 Published: February 25, 2021

doi:10.5296/emsd.v10i2.18360 URL: https://doi.org/10.5296/emsd.v10i2.18360

\begin{abstract}
The European Union Forest Law Enforcement on Governance and Trade (EU-FLEGT) Action Plan seeks to promote widespread sustainable forest management and relies largely on transnational actors and international law in its operationalization. The EU FLEGT sets out EU custom regulation through Voluntary Partnership Agreements (VPAs) which is a bilateral agreement between the EU and wood exporting countries with instruments aimed at promoting sustainable practices within the forest resources value chain. Ghana became a signatory to the FLEGT VPA since 2007, as part of the process, it is required to use technology to track timber logging from source to point of export. Issues of networks and inter-agency collaboration and dealing with human elements remain crucial in ensuring effective operationalization. Adopting a qualitative case study design as well as theories and concepts from the public policy implementation literature, this study examines the implementation vagaries of the FLEGT VPA in Ghana. Although the VPA is a laudable idea of using Information Technology (IT) in effectively tracking timber to its original source to ascertain legality or otherwise of the timber, the needed IT infrastructure and resources have not matched up with the goal. Additionally, the VPA implementation is expensive and has come with additional cost to the implementers, The study further observes that the increasing 'red flags' that are raised on the Ghana Wood Tracking System is a blend of technical errors emanating from negligence or capacity challenges and human manipulation. This calls for regular consultations and workshops with relevant stakeholders in order to assess which skills
\end{abstract}


are deficient and a need to beef up through on-the-job training. The domestic market and trading activities tend to fuel demand for illegal timber hence a constraint to the full realization of the VPA objective. The study makes policy suggestions on how to address these implementation challenges.

Keywords: FLEGT, VPA, Forest Governance, Technology, Collaboration, Implementation

\section{Introduction}

Policy-makers world over have come to terms in their national forest plans and in the international forest policy arena the relevance of sustainable forest management to reduce forest loss and enjoy the benefits associated with sustainable ecology (McDonald \& Lane, 2004). Deforestation and forest degradation remain the second leading anthropogenic cause of carbon dioxide emissions which continues to increase global warming (Intergovernmental Panel on Climate Change, IPCC, 2007).

The European Union Forest Law Enforcement on Governance and Trade (EU-FLEGT) Action Plan seeks to promote widespread sustainable forest management and relies largely on transnational actors and international law in its operationalization. The EU FLEGT sets out EU custom regulation through Voluntary Partnership Agreements (VPAs) which is a bilateral agreement between the EU and wood exporting countries with instruments aimed at promoting sustainable practices within the forest resources value chain. The EU is a valuable market destination for Ghana which accounts for forty-three per cent of the value of total exports and thirty-three per cent of total volume ${ }^{2}$. Ghana's share of the EU's tropical timber imports is about $3 \%$. Consequently, the EU is valuable wood trade partner to Ghana, the latter has subsequently become a signatory to the VPA since 2007 and is therefore required to adequately put in place robust governance systems and structures to meet the criteria as set out, which should have implications on sustainable forest management.

The FLEGT VPA is only a policy intention but its effective enforcement to engender sustainable forest management practices requires robust technologies, prudent systems and committed human resources as well effective inter-agency cooperation among implementation officials, meanwhile, the policy implementation literature contends that these ideals are mostly illusive. According to Dye (2008), public policies may regulate behavior, organize bureaucracies, distribute benefits or extract taxes. The policy implementation is of critical importance to the success of government; however good the political system, however noble the goals, however sound the organizational structure, no policies can succeed if the implementation does not bear relationship to the intentions of the policy adopters...studies show that the implementation stage is the most important and yet the most neglected" (Sapru 2010, p.149). Policy implementation entails those processes, resources and mechanisms as well as the relationships that combine public policies (Mthethwa, 2012). Ensuring successful implementation is a function of the right combination of committed bureaucrats and how best hostile and apathetic groups are managed and more importantly the extent to which the policy environment is well insulated from the vagaries of implementation (Ayee, 2000). It is also instructive to reckon that kind of reaction that relevant stakeholders and the general public exhibit towards the said policy or intervention would determine whether the policy will be 
effective or poorly enforced (Grindle \& Thomas, 1989).

Grindle and Thomas (1989) assert that reaction from the public towards the new policy or reform determines the success or the failure of a policy. Van Meter and Horn (1975) explain that factors that account for successful implementation of public policies include various aspects such as organization structures; human resources; finance; materials and equipment as well as innovation and technology. Hunter and Marks (2002) argue that successful implementation involves not just a common agenda and long-term joint commitment across different agencies but a degree of transparency about the model being adopted.

Ghana became a signatory to the FLEGT VPA since 2007, as part of the process, it is required to use technology to track timber logging from source to point of export. Issues of networks and inter-agency collaboration and dealing with human elements remain crucial in ensuring effective operationalization. Adopting theories and concepts from the public policy implementation literature, this study examines those elements that militate against the effective implementation of the FLEGT VPA regulations in Ghana. The study further proposes measures to navigate through these challenges in order to ensure effective implementation.

\section{Theoretical Framework}

\subsection{The Complexity of Joint Action}

The policy process comprises diverse set of actors who interact at different stages to get the policy effectively implemented (Lester \& Stewart 2000). These different set of actors ideally are expected to act towards a common objective of successful implementation which requires collaboration and cooperative efforts theorized as 'joint action'. That notwithstanding, the reality is that actors in the implementation process in many instances have divergent viewpoints, interests, demands and expectations which are mostly conflicting and makes it compounded in reaching consensus and joint actions. The process becomes complex as it requires bargaining, cooperation, consensus and compromises by different set of actors who mostly may have conflicting interests (Ayee, 1992). Following from above school of thought, Pressman and Wildavsky (1974) postulate that actors in the implementation phase tend to approach the process with divergent perspectives which may have a tendency to affect the implementation process. Meanwhile, Ayee (1992) maintains that complexity of joint action arises due to the numerous arrays of actors whose cooperation is required before a policy gets effectively enforced. This is what is termed as complexity of joint actions. Applying this theory to the study, that forest resources provide different stakeholders with different values and these are mostly conflictual. For example, whilst timber companies and individual loggers seek to maximise their lots from forest resources by harvesting as many as possible timber and monetize these with minimal costs, foresters and other government officials are interested in ensuring sustainable harvesting and management of forest resources are maintained. Some of those actors in the latter group also have their economic motive which may make them oblivious of their mandate and likely to collude with the former. This whole arrangement makes joint action between all foresters and other government officials in the implementation value chain somewhat compounded and the joint action between foresters 
and implementation officers even gets mor murkier due to the apparent conflicting interests.

Again, as Van Meter and Horn (1975) contends various drivers of policy implementation success involve elements such as organization structures; human resources; finance; materials and equipment as well as innovation and technology, it should be noted that the provision of these resources especially finance, materials, equipment and technology is provided by government and the willingness to commit these resources to either the Forestry Commission or any other public sector agency in itself involved complexities such that the idea of who gets what, when and how comes into play. Hunter and Marks (2002) contend that successful implementation involves not just a common agenda and long-term joint commitment across different agencies but a degree of transparency about the model being adopted, the extent to which all relevant stakeholders especially implementation officials will stay committed to the common good of prudent implementation of regulations is required yet problematic to achieve.

A main strong point of the 'complexity of joint action' model is that it directs policy actors on the challenges inherent in the policy space which enjoins various policy actor to advance their interests through effective bargaining, lobbying and other relevant approaches.

\section{Methodology}

The case study design within the qualitative research approach of social research was adopted for the study. The purposive sampling technique was used to select relevant informants to participate in the study. With qualitative study, researchers do not place much emphasis on numbers but the quality of information that would be elicited from participants (Sandelowski, 1995). Both primary and secondary sources of data were used to undertake the study. Primary data was elicited from respondents along the value chain of enforcing Ghana's VPA.

The purposive sampling technique was used to select fifty-nine (59) key actors from the Forestry Commission which is the lead government institution for VPA implementation in Ghana and expected to contribute about eighty per cent of VPA implementation. A newly created TVD at FC coordinates VPA implementation process. Key administrative and implementing officials of the relevant units/departments at the Forestry Commission; relevant committees/councils and working groups for VPA implementation and a VPA Secretariat as well as participants from the Ministry of lands and natural resources. Key actors from the Resource Management Support Centre (RMSC), the Forest Service Division (FSD) and the Timber Industry Development Division (TIDD) of Ghana's Forestry Commission were selected. Tropenbos International, a non-state organization which has been active in VPA processes was selected.

Secondary data involved materials from journal sources, scholarly books, internet sources, published and unpublished materials relevant to the study. Again, documents from Ministry of lands and natural resources, Forestry Commission of Ghana; Ghana-EU team bulletins and other releases were resorted to.

The main instrument for primary data collection was through the use of in-depth interviews and semi-structured questionnaires. In-depth interview involves face-to-face interaction with 
key respondents. Data was recorded and transcribed which was subsequently organized through thematic analysis.

\section{Analysis and Discussion}

\subsection{Analysis}

In an attempt to examine the implementation constraints, respondents were first asked whether the implementation process of the VPA has been smooth or not. All respondents provided a negative response to this question to suggest that the VPA implementation process is shrouded with multiple enforcement challenges. Respondents discussed the fundamental challenges which affect the smooth operationalization of the VPA and its objective of ensuring sustainable forest management. The main themes which emerged from the data are presented and discussed below:

\subsubsection{Logistical Constraints and Cost}

A major challenge which affects the effective implementation of the VPA is the issue of poor network connectivity. This is a big blow to the VPA implementation because significant aspects of the process is electronic and network based hence would ideally require information technology devices such as specialized laptops, GPS devices, and reliable connectivity of the systems at the national level, district levels and the field. An assistant regional manager in Kumasi explained:

A major setback is connectivity problem, poor connectivity at the district and regional levels; inadequate devices such as GPS, Handheld Computer, Laptop etc; Old vehicles for effective monitoring (Asst Regional Manager, Kumasi)

The issue of logistical constraints and internet connectivity setback was corroborated by a manager in Asankrangwa District who intimated:

"the implementation has not been all that smooth due to network problem and lack of training for field staff... there is the need to improve the infrastructure for GWTS for an effective real time data capture and processing.

From the above narratives, logistical challenges especially internet connectivity affects the timely capture and processing of data. In other words, poor internet connectivity necessarily affects the very purpose of the VPA which is to foster real time data for decision making on the legality of timber or log.

Beyond the logistical constraints, it was observed that the VPA has also come with additional cost to the Forestry Commission. Such cost component makes effective enforcement and monitoring problematic which also reduces the effectiveness of monitoring and supervision. A senior manager at the RMSC explained:

The implementation of GHLAS, WTS, FLEGT license and effective forest monitoring is costly because of logistics, personal fuel and payment of allowances

The financial burden is estimated to exacerbate if the project tenure comes to a closure. A district administrator at Goaso explained: 
"when we are left to stand after the full process is completed, there would not be funding for VPA implementation. However, currently operational cost associated with the TLAS implementation is borne by the Forestry Commission.

The narrative above was corroborated by an assistant verification officer at the Timber Verification Department (TVD) of Forestry Commission. He explained:

"TVD audit and cost of maintenance and running cost if the current funding elapses"

This suggests that efforts should be made to explore alternate measures to raise additional income to support the effective implementation of the VPA even when the external support comes to a closure. This is because the VPA process is believed to have an overall impact on sustainable forest governance in Ghana. In their study in Ethiopia, Teketay et al (2010) found that logistical constraints affect effective monitoring and supervision of the stipulated forest regulations which in the long run reduce the efficacy of institutions. The finding is also in agreement with Carabelli et al (2007) who after employing some quantitative techniques reckoned the need to pay crucial attention to resource administration, monitoring of resource use, and transparency in forest use. This suggests that resources are very crucial in the enforcement of forest policies such as VPA and in a situation of inadequate resources other key interventions such as monitoring and supervision, tracking of wood among others cannot be operationalized more effectively.

\subsubsection{Red Flags}

It also emerged from the study that the computation process where field officers code trees and timber unto the software sometimes pops up entry errors. This is what is termed as 'red flags' which may suggest either an error on the part of an official or technical problem. In situations where the software generates many red flags, it becomes more frustrating to field officials when genuinely there has not been any tempering of the tree species or software. An administrator at Asankrangwa Forest Services Division explained the red flags phenomenon:

Renting of the previous compartments which stock (survey) are not synchronized into the system creates red flags.

It emerged from the study that although in theory the trees in the field have to be earmarked and identified, in practice this ear marking at times is relegated to the background which may also raise some red flags. An administrator at the FC remarked:

"I thought some survey numbers have to be tagged on the trees... the position of the trees has been neglected on the GIS coordinates

Observing the potential setbacks that may be associated with technology in forest management and nature conservation, Arts et al (2015) warn against the tendency of hyping the benefits, 'techno-fix' philosophy as well as unsubstantiated expectations on promises and short-term benefits. The observation of red flags with the VPA or WTS system needs to be further monitored to ascertain the extent to which it is due to human error or with the system itself. The empirical literature has reiterated the need to evaluate impact of IT on forest conservation and to counter the biases or penchant for good news narratives (Arts et 
al., 2015, 2013; Newey et al., 2015) which may commonly report less on the challenges, constraints, debacles and failures that many projects may fail. In this regard the occurrence of red flags with the WTS system needs to be investigated on case by case basis to determine if indeed there is a trend of human error, collusion or with the system itself.

\subsubsection{Institutional Capacity of Actors not Fully Developed}

The study found out that technical know-how of implementation officials at the FC have not been fully developed to match up with the new tasks that VPA enforcement has brought. An officer at the Sunyani TIDD mentioned:

"GWTS requires knowledge on computer, however, those of us not well versed in it have a lot of challenges in inputting data. Delay in input data from FSD making our work difficult

Besides, most of the agencies need to be harmonized and coordinated to ensure smoother implementation of the process and this has not been complete. Respondents maintained that the institutionalization process is not complete and there are many processes that need to be streamlined. An Assistant Regional Manager explained:

The Ministry of Lands and Natural Resources needs to come out with policy framework involving inter and intra departmental agencies to develop institutional structures for VPA.

\subsubsection{Inter-agency Coordination}

Very related to the capacity challenge above, the study observed laxities in inter-institutional coordination in the implementation of VPA. In other words, collaboration between relevant agencies and institutions for the purpose of VPA implementation is problematic since there are not clear cut regulations which explicitly clarify the roles or functions of each actor. When asked on the level or nature of collaboration between actors or agencies, an assistant Regional Manager explained the practical constraints since there is no such benchmark against which a determination could be made. He contended:

"It is difficult to determine the level of collaboration as the expected roles and functions of the collaboration are not visible".

This point was given support by a key participant from the Sunyani area TIDD who mentioned that inter-sectorial collaboration and trust issues tend to result in double-jeopardy or double checking of consignment. He gave an illustration:

"low level of collaboration exists now because each department still sees themselves as autonomous. FSD still arrests vehicles that have genuine TIDD documents all because of mistrust among various divisions.

However, one of the respondents at Asankrangwa Forest District explained that the level of collaboration is high as a result of numerous meetings and workshops. This position was given support by an administrator with over 21 years' experience who noted: 
"It has been cordial with TIDD regarding data input and verification for instance of the LIC and DOSIC. Unlike previously where collaboration was poor in this regard.

\subsubsection{Illegal Domestic Timber Trade}

It emerged from the study that the domestic timber trade has been a torn in the flesh of the VPA implementation since it provides a market for timber from illegal source. The point is that once there is a ready market for such products, suppliers will try all means to meet the demands. A senior manager at the RMSC put forward:

"The mixing of different wood and situations where illegal wood finds its way unto the domestic market is difficult for alluding to the fact that these logs were coming from legal sources.

This is a challenge to VPA implementation because woods sold in the domestic market presently are not subjected to the kind of scrutiny those for the EU market will go through. At the final point of departure to the port, any illegal source would have been detected but unfortunately with the domestic market such checks will not apply. A key informant explained:

"if the wood is sold in the country, the EU community cannot detect the source of it as either it is legally felled or illegally felled" (Snr Manager, RMSC)

This point was given support by an assistant manager at the RMSC who noted:

The local market and consistent illegal chain sawing and logging has been a major challenge. The domestic timber trade affects the VPA process because they are mostly from illegal sources and provide demand for illegal logging... There is difficulty in tracking to the plantation timber stump as done for natural forests...there has been the lack of agreement for a long time on whether the WTS should be applicable or not (manager, plantation RMSC)

\subsubsection{Uncooperative Attitude of Domestic Operators}

The study also observed some undercurrents of some reservations among local timber merchants who think the strict enforcement of VPA and its timber legalities will affect their interest. A private timber merchant put it:

"Gross disregard for issues/concerns raised during consultations; obsolete and impractical prescriptions/regulations and unresolved nagging legal battles...the VPA is originally an EU project and therefore implementing domestically has its inherent challenges. (Forest manager, Samatex Timber \& Plywood Co.)

The finding above in agreement with an observation by Górriz-Mifsud et al (2019) who in a cursory review of forests in Navarra (Spain) observe that cooperating to manage forest resources suggests a decrease of transaction costs for all members and helps to optimize the coherence of forestry actions yet the process of arriving at and maintaining a more concerted effort from participating forest owners is very difficult. 


\subsection{Addressing the Challenge}

In order to address the above challenges, respondents proposed some workable solutions which will help ensure smooth implementation of the VPA. From the discussions with respondents, the following themes have been identified and discussed.

\subsubsection{Consultations and Workshops}

The inter-agency coordination problem and the challenge of ensuring cooperation among relevant stakeholders can be addressed through effective stakeholder consultations and workshops. This will be a platform to bury the differences, build bridges across differing groups through education, sensitization and compromises. A key respondent from the Ashanti Region explained that ensuring a workable process calls for workshops with interested parties. He explained:

The challenges could be solved through consultative workshops and collaboration with identified stakeholders

\subsubsection{Reducing Red-Tapeism}

Domestic timber trade violation of VPA regulations can also be best addressed through such workshops where measures can be put in place very tailor-made to suit the particular realities and containment capacities of these informal and formal groups. This is against the backdrop that the bureaucracies and difficulties in obtaining permits and licenses before one can operate a chain saw are too cumbersome which demotivate people and so resort to unorthodox processes. An Assistant District Manager at Asankrangwa put this forward:

"Difficulties in obtaining permits and licenses tend to frustrate many operators who in the process give up or the perception alone will not make people come to us for permits and they operate unregulated, but if they had come to us, at least they will be regulated and will comply with some minimum standards".

\subsubsection{Enhancing the Process with GPS}

In order to make the GWTS operate more effectively, it is crucial to procure appropriate and sufficient logistics and the necessary IT infrastructure. To reduce the phenomenon of red flagging which mostly pops up on the system, the use of GPS in the coding process will be helpful. An administrator suggested:

"I suggest we should revisit the bar code tagging during stock survey. GPS location of trees should be incorporated during the stock survey to help in identifying tree locations

A major problem which came out was connectivity problems and internet which in most cases lead to a disconnect between the district offices and headquarters. To address connectivity problems, respondents provided a technical solution. An assistant regional manager in Kumasi highlighted:

"to address the connectivity problems, there should be holstering of services at the 
regional offices and also installation of solar panels and inverters for continuous power supply.

\subsubsection{Capacity Building}

Finally, it is more important to build capacity of forestry officials in the software and processes required for the VPA implementation. The process should be an ongoing one and on the job such that periodic workshops on the software and to address the peculiar challenges faced by field operators and those along the value chain. An administrator at the Asankrangwa forest district intimated:

“all staff of FSD including Resource ....... representatives e.g., filing clerks, should be trained very well on the use or the process of GWTS"

Capacity building should also come with adequate logistics and other relevant resources to help them operate more effectively. In other words, a trained official without the necessary tools and equipment to operate will still appear incapacitated and so capacity building must come accompanying resource to help function more effectively. For example, a systems data manager narrated:

"The field officers must be retooled in terms of equipment and logistics, this will help them execute or put into practice what has been learnt... without the tools or logistics, how do they put in practice?

\subsubsection{Monitoring}

To enhance the implementation of VPA, an assistant district manager recommended a strict application of the seven principles stipulated in the VPA document which are: sources of timber, timber rights allocation, timber harvesting operations, transportation, processing, trade, fiscal obligations

The task force and the marketing team should fight illegalities from the forest gate (asst manager, RMSC); however, there is a challenge where there are counter actions by some powerful actors (manager, FC), political will is therefore key in ensuring sanity

The recommendation above is agreement with a similar one by McGinley and Cubbage (2012) who in their comparative evaluation of government's regulation of forest in Costa Rica, Guatemala, and Nicaragua who after observing inadequate organizational structures, resources and processes for policy SFM policy enforcement recommended the need to optimize the monitoring mechanisms for forest governance.

\subsubsection{Institutional Reforms}

Respondents proposed the need for continuous reforms of the rules and regulations governing the forest sector. The point here is that whether the forest sector will be managed well or not will depend on the rules of the game, therefore it is crucial to periodically monitor and audit the institutional underpinning to find out the loopholes in order to address these. A respondent from a timber company intimated: 
"Existing impractical /obsolete policies to be revised to suit contemporary forestry business. Definition of legal timber to encompass all legal sources of timber in Ghana (forest manager, Samatex)

The participant further intimated that due to the changing circumstances, it is also important for forestry commission to be updating its regulations so as to be in tune with realities of the time. For example, the respondent mentioned that the definition of legal timber should open the scope to accommodate all legal timber.

This point was corroborated by an assistant verification officer at the TVD highlighted:

"Continuous improvement in institutional processes and ensuring that audit findings are implemented and where possible punishment are meted out without fear or favor

From the above narrative, the participant made a case for improving the institutional processes and to effectively enforce findings without being compromised. People who flout the rules are to be sanctioned to serve as deterrence.

\subsection{Conclusion and Policy Suggestions}

From the observations and discussion above, the study draws the following conclusions.

Firstly, the implementation of the VPA has been hampered due to logistical constraints and has also posed additional cost to the Forestry Commission. Although the VPA is laudable idea of using IT in effectively tracking timber to its original source to ascertain legality or otherwise of the timber, the needed IT infrastructure and resources have not matched up with the goal. Additionally, the VPA implementation is expensive and has come with additional cost to the FC, the study concludes that without proper mechanisms of funding the VPA upon expiration of the initial project, the VPA is likely to face deep-seated challenges.

Secondly, the study observes that institutional capacities of the relevant FC officials have not been sufficiently developed to enforce the VPA which leads to some implementation errors in the process. The study concludes that the increasing red flags that are raised on the GWTS software is a blend of technical errors emanating from negligence or capacity challenges and human manipulation. This calls for regular consultations and workshops with relevant stakeholders in order to assess which skills are deficient and a need to beef up through on-the-job training.

Despite the VPA is implemented via various agencies along the timber value chain, the study observes that inter agency-coordination has not been properly enhanced. The study concludes that institutional coordination has been an issue which constrains the full optimization of the VPA implementation process.

Additionally, the domestic market and trading activities tend to fuel demand for illegal timber hence a constraint to the full realization of the VPA objective. The VPA tends to use demand for timber products as a condition to compel loggers or companies comply with legality standards yet the illegal domestic timber trade provides ready market to every timber irrespective of its source. The study concludes that effective implementation and realization 
of the VPA objectives requires a full incorporation and harmonization of the domestic timber market. Without aligning the two domains, VPA enforcement will be very difficult. This also requires reducing the red-tapeism involved in registering or obtaining permits for legal lumbering which will reduce the tendency for individuals to indulge in illegal timber logging.

\section{References}

Arts, B., Behagel, J., Turnhout, E., De Koning, J., \& Van Bommel, S. (2013). A practice-based approach to forest governance. Forest Policy and Economics, 49, 4-11. https://doi.org/10.1016/j.forpol.2014.04.001

Arts, K., van der Wal, R., \& Adams, W. M. (2015). Digital technology and the conservation of nature. Ambio, 44(4), 661-673. https://doi.org/10.1007/s13280-015-0705-1

Ayee, J. R. (1992). An anatomy of public policy implementation: The case of decentralization policies in Ghana.

Dye, T. R. (2008). Understanding Public Policy (12th ed.). Upper Saddle River, NJ: Prentice Hall

Grindle, M. S., \& Thomas, J. W. (1989). Policy makers, policy choices, and policy outcomes: The political economy of reform in developing countries. Policy Sciences, 22(3-4), 213-248. https://doi.org/10.1007/BF00136320

Hunter, D. J., \& Marks, L. (2002). Decision-making processes for effective policy implementation. National Institute for Health and Clinical Experience Guidance Paper. [Online] Available: http://www.nice.org.uk/niceMedia/pdf/SemRef_Decision_Hunter.pdf

IPCC. (2007). Fourth Assessment Report. International Panel on Climate Change. [Online] Available: https://www.ipcc.ch/assessment-report/ar4/

Lester, J. P., \& Stewart, J. (2000). Public Policy An Evolutionary Approach. Wadsworth, Stamford, USA.

McDonald, G. T., \& Lane, M. B. (2004). Converging global indicators for sustainable forest management. Forest policy and economics, 6(1), 63-70.

https://doi.org/10.1016/S1389-9341(02)00101-6

Pressman, J., \& Wildavsky, A. (1984). Implementation (3rd ed.). Berkeley: Carlifornia University Press.

Sandelowski, M. (1995). Qualitative analysis: What it is and how to begin. Research in nursing \& health, 18(4), 371-375. https://doi.org/10.1002/nur.4770180411

Sapru, R. K. (2010). Public Policy: formulation, implementation \& Evaluation. Sterling, Okhla: New Delhi.

Van Meter, D. S., \& Van Horn, C. E. (1975). The policy implementation process: A conceptual framework. Administration \& Society, 6(4), 445-488.

https://doi.org/10.1177/009539977500600404 


\section{Macrothink \\ Environmental Management and Sustainable Development \\ ISSN 2164-7682}

\section{Copyright Disclaimer}

Copyright for this article is retained by the author(s), with first publication rights granted to the journal.

This is an open-access article distributed under the terms and conditions of the Creative Commons Attribution license (http://creativecommons.org/licenses/by/4.0/). 